\title{
Self-Assessment of Self-Advocacy Skills Among Students with Special Needs
}

\author{
Dr. Burhan Mahmoud Hamadneh \\ Department of Special Education, Faculty of Education, Najran University, Kingdom of Saudi Arabia \\ Pox 1988, Najran,22451, Najran University, Kingdom of Saudi Arabia
}

\begin{abstract}
Although universities provide an equivalent opportunity to provide students with the necessary education services and support, students with learning disabilities still experience academic and personal challenges at the university settings. However, students need to know how to advocate themselves in order to acquire the necessary assistant. Therefore, this study aimed at developing framework to provide students with learning disabilities with the required supports and service at the different levels of the university as well as to improve self-advocacy skills among students with learning disabilities. 8 students participated in this study and qualitative method was adopted. The finding showed that students scored moderate level of self-advocacy as well as some suggestion and recommendation were reported by the students as additional supports and services are needed at the university level.
\end{abstract}

Keywords: Self-Advocacy, Education, Student, University.

DOI: $10.7176 / \mathrm{JEP} / 12-33-12$

Publication date: November $30^{\text {th }} 2021$

\section{Introduction}

In the past thirty years, focus and concern has been consistently placed on paving opportunities for all people to acquire education, with the inclusion of those that are disable (Boer \& Kuijper, 2020; Barnett, 2014; Reed et al., 2011). The majority of students and students with disability have learning problems (Jdaitawi, 2020; Jdaitawi, 2020; Sloane, 2016; Jdaitawi, 2019; Jdaitawi, et al., 2013; Jdaitawi et al., 2014), they are more susceptible to suffer from psychosocial and academic challenges compared to their peers (Reed et al., 2015; Thompson-Ebanks, 2013). Therefore, students have a key and active role to play in searching for and obtaining academic support, calling for the development and usage of effective self-advocacy skills (Kinney\&Eakman,2016). Self-advocacy is referred to as the ability of the individual to communicate his/her needs and wants in an effective manner to reach decisions concerning the required support in social and academic achievements (Haas and Phinney, 2013). Self-advocacy in academia can boost students' success as documented by several studies and among the benefits mentioned are developed self-esteem, easing the way to master a difficult academic skill, maximizing social activity, and enhanced academic success of students (e.g., Robert et al., 2016; Andrews, 2018).

Students that display self-advocacy skills can express their perceived academic strengths and weaknesses clearer than those who do not (Andrews, 2018). According to Roberts, Song and Zhang (2016), effective selfadvocacy instruction in students having specific learning disabilities often lead to behavior that is consistent with increased study achievement and successful academic endeavors. In relation to the above, self-advocacy instruction outcomes in students with distinct learning disabilities reflect actions that are consistent with increased education and academic achievement and success, more so in the college level although majority of studies were conducted on students in school level. This was highlighted in Geffen's (2013) study, which mentioned that studies on the way students acquire self-advocacy skills, the timing, and the reason behind their use at the student's level are still a few and far between. Also, only a few research studies have mentioned the youth acquisition of self-advocacy skills, with fewer that examined the way and the timing that students use such skills in the university setting (Daly-Cano et al., 2015). Similar statements were mentioned by Roberts et al. (2016), who indicated limited studies identifying the way students with disabilities acquire self-advocacy skills if their acquisition does not involve their peers, instructors or members of their families.

Self-Advocacy was described in the literature as one construct that is being very important for successful transition from school stage to university life for individual with disabilities (Kissel, 2006; Walker \& Test, 2011). Literature on self-advocacy argues that students frequently lack self-advocacy and professional remedial coaching interventions are needed to help students to be successful (Vaccaro \& Kimball, 2017; Karpicz, 2020). by Gil (2007) and (Roper, 2016) confirmed that the more practice the students have encountered in selfadvocating in their study, the more they will success in their transition period. Despite the presence of the need to self-advocate at the student level, research on students' acquisition of self-advocacy skills (the how, when or why) are still limited (Geffen, 2013). Similar findings were found by prior studies (e.g., Roberts et al., 2016; Hartley \& Stuntzner, 2015) in that only a few studies highlighted the how, where and when of students with disabilities when it comes to self-advocacy skills acquisition if such acquisition did not involve educators, peers or family members. Literature along this line showed a need to investigate these skills effectiveness in relation to 
the students' study completion, particularly students suffering from disabilities (physical or cognitive) (Sisk, 2019). According to Roberts et al. (2016), research are required to pinpoint the effectiveness of self-advocacy instruction outcomes in students with distinct learning disabilities.

Tedla and Negassa (2019) conducted a study to identify self-advocacy skills among blind university students in Ethiopia. Negative results were found as blind students indicated that they were unable to be selfadvocates for their inclusion. Roper (2016) also investigated the effect of self-advocacy intervention on students with disabilities self-advocacy skills. The result intervention positively enhanced student's self-advocacy skills. Karpicz (2020) and Daly-Cano et al. (2015) also highlighted that self-advocacy is a critical practice that help students with disabilities in improving their retention and increasing their success. To compound the matter further, existing studies largely focused on schools' students and therefore, self-advocacy information on the level of university students with learning disabilities call for more studies to fill the literature gap (Andrews, 2018; Tedla, 2017; Roberts et al., 2016). When it comes to university students, special support services appear to be the most appropriate context through which students' learning disabilities can enhance and support their selfadvocacy skills. Thus, in essence, the present study contributes to the education field by pinpointing the perspectives of university students with specific learning disabilities in regard to the specific type of educational support required and provided as well as specific self-advocacy knowledge and rights elements affecting selfdisclosure and search for support in universities. This may have implications to educational institutions as to the provision of effective self-advocacy teaching, to direct the students' preparation towards achieving their goals and to always be prepared. Thus, this study aims to determine the answers to the following research questions:

1- Do support and activities provided to students with learning disabilities and needs impact their selfadvocacy from their perspective?

2- What suggestions would students report to assist those with learning disabilities and needs in the context of university?

\section{Methodology}

This study primarily aims to examine if instruction of supported sources is related with increased self-advocacy skills among students with learning disabilities, following their exposure to several sessions on its potential advantages. The study used an exploratory collective case studies approach. The case study approach was appropriate for investigating real life experiences among participants The study adopted a qualitative method approach, to achieve the study objective. The choice of using qualitative method as the study focused on the effect of the university services provided to enhance students with disabilities self-advocacy by interacting effectively with their peers and university staff.

\section{Sample}

The exploratory study was toke place at one university in south region. The place was chosen since the university provided students with more service and treat them confidentiality. Eight participants took part in the present study and benefited from the offered sources at the university. All students were in their first degree and affiliated with the school they attended. The sample's mean age was 18-22 years, and students comprising the sample were questioned if they sought assistance from their instructions, if they were with learning disabilities and undergone the provided sessions. The researcher received approval to conduct this study from the university where the study was conducted.

\section{Measurement}

The measurement used to gauge self-advocacy was Self-Advocacy Interview for Students (SAI) taken from Brunello-Prudencio (2001). Specifically, the former comprised of 3open ended questions. Three questions were highlighted such as; If you need assistance due to your learning disability/needs, what materials would you need to provide in order to report your disability? If you need assistance due to your learning disability/needs, when and to whom would you deliver it? Were the services provided by the college helpful in achieving your needs and do they support you in succeeding in your studies so far?

\section{Results of the Study}

Three questions were answered by students in order to show their feedback about supported services. The results of the 8 interviews somehow confirmed the answers to the qualitative questions. First question, if you need assistance due to your learning disability or needs; what materials would you need to provide in order to report your disability? Regarding to the first question "what materials would you need to provide in order to report your disability", the result showed that 6 out 8 students indicated that they colleges should organized a weekly individual and group meeting with students with learning disability as well as they would contact a specialist or disable coordinator. The other two students indicated that they do not need to provide anything as they can ask for help whenever needed. Second question, if you need assistance due to your learning disability or needs; when 
and to whom would you deliver it? Regarding to the second question "if you need assistance due to your learning disability or needs; to whom would you deliver it"? 6 students indicated that they would contact specialist or disable coordinator regularly, and the other two students indicated that they would contact their respected teacher directly whenever needed. Third question, were the service provided by the college helpful in achieving your needs and do those supports help you to success in your study so far? Regarding to the third question, "were the service provided by the college helpful in achieving your needs and do those supports help you to success in your study so far?" 5 of the students indicated that the supported services provided were helpful, another two students stated that some services were helpful but not all; and the other one answered that the supported services were not sufficient as the colleges need to ensure that the class environment is safe and the activities and classes need to be prepared with the adequate time that suit their needs.

\section{Discussion}

In the context of educational institutions, self-advocacy skills have been described as an important tool that students with learning disability can avail from to succeed in their academic endeavors. The universities offer different services to assist students in obtaining advocacy skills and in regard to this study, the importance of such skills in a university setting is examined. For the first interview question (what materials would you need to provide in order to report your disability?), 6 from 8 students interviews revealed the need for their colleges to organize weekly individual and group meetings with students with learning disability, for consulting specialists and for consulting a relevant coordinator. The remaining two stated that they did not need to provide anything and that they can request for assistance when needed. Moving on to the second interview question (if you need assistance due to their learning disability/needs, to whom would you ask for it?). Six out of eight students showed that they would ask a specialist/coordinator for students with disabilities on a regular basis, while the other two opted to contact their instructors directly when need be. Lastly, for the last question (were the services provided by the college helpful in achieving your needs and do they support your success in your study so far?), five out of 8 students described the services as helpful, two described some of the services as helpful but not all, while the remaining student stated that the services were not sufficient in supporting the safety of the class environment and more activities and classes need to be organized and prepared, with adequate time to be conducted, to meet the needs. Some suggestions also were highlighted by the students such as organizing some activities which may help them to adjust at the university and seek for help whenever needed without any negative feeling as we as the activities should be given by specialists who can give their right directions towards their learning and visited them whenever needed in order to improve their self-advocacy and achieve their learning outcomes. The results of the student may be due to the fact that students may need other support forms that are appropriate to fulfill their needs. Literature (Tagayuna et al., 2005) supported those students with learning disabilities may benefited from the support services provided in the university. Still another reason may be because the college support should be in the form of counseling and advising units focusing on activities and sessions to assist students with learning disabilities. The activities may be provided through academic workshops involving memorization aids, active communication and reduced exam anxiety.

\section{Limitation and Recommendation}

The participants to this study numbered eight students, and in this regard, future studies may include more participants. In the same way, some factors were excluded from this study like family and environmental factors, and thus, future studies may examine their effect on the self-advocacy skills of university students. In addition, each university has its agenda for support students with learning disabilities and thus, agendas may be compared by future studies to reach the best practices/ policies that are suitable to this specific population. The present study obtained the students' perceptions of the support provided by the universities, so future studies may instead obtain the perceptions of instructors to provide insight into the other services provided by the university to facilitate the process of learning and teaching. The study defined students with learning disabilities as those that seek assistance for their health issues or cognitive issues, and for this, future studies should clarify their definition in order by conducting a comparison between them and those without disabilities.

\section{Conclusion}

This study's main objective is to highlight the support services for students with learning disabilities provided by the universities and stressed on such services accordingly. Thus, the study minimizes the literature gap by specifically investigating the study focus and by developing a model to enhance the self-advocacy of students with learning disabilities and to discern what they can benefit from the supporting model. The study provides a synthesis of the findings regarding the academic services that improve student's self-advocacy among the participants of this study, and provide general conclusions across the services provided in the qualitative data. The results suggest that the students participated in this study demonstrated some improvement in using their self-advocating behavior. The study results confirmed that university students with learning disabilities have 
self-advocacy skills at the university level, but the factors examine are limited and thus, further studies are needed to include other factors relevant to students with learning disabilities.

\section{References}

Andrews, M. (2018). Improving self-advocacy skills in secondary education students. Unpublished Master Thesis, Goucher College.

Barnett, L. (2014). Evaluation of relationship between self-advocacy skills and college freshmen first semester grade point average for students with disabilities. Graduate University Thesis, University of Montana.

Boer, A. \& Kuijper, S. (2020). Students voices about the extra educational support they receive in regualr education. European Journal of Special Education. http://doi.org/10.1080/08856257.2020.1790884.

Brunello-Prudencio, L. (2001). Knowledge and communication skills training for high school students with learning disabilities for the acquisition of self-advocacy skills. (Doctoral dissertation). Available from ProQuest Dissertations and Theses database. (UMI No. NQ58985).

Daly-Cano, M., Newman, B., \& Vacarro, A. (2014). College student narratives about learning and using selfadvocacy skills. Journal of Postsecondary Education and Disability, 28(2), 213-227.

Daly-Cano, M., Vaccaro, A., \& Newman, B.M. (2015). College student narratives about learning and using selfadvocacy skills. Journal of Postsecondary Education and Disability, 28(2), 209-223.

Gil, L. (2007). Bridging the transition gap from high school to college: Preparing students with disabilities for a successful post-secondary experience. Teaching Exceptional Children, 40, 12-15

Haas, K. \& Phinney, J. (2013). The process of coping among ethnic minority first generation freshmen: A narrative approach. The Journal of Social Psychology, 143(6), 707-726. http://doi.org/10.1080/00224540309600426.

Hartley, M., \& Stuntzner, S. (2015). Balancing self-compassion with self-advocacy: A new approach for persons with disabilities. Annals of Psychotherapy and Integrative Health, 17(1), 12-28.

Jdaitawi, M. (2019). The effect of flipped classroom strategy on students learning outcomes. International Journal of Instruction, 12(3), 665-680.

Jdaitawi, M. (2020). Does flipped learning promote positive emotions in science education? A comparison between traditional and flipped classroom approaches. Electronic Journal of e-learning, 18(6), 516-524.

Jdaitawi, M. (2020). The effect of using problem-based learning upon students' emotions towards learning and levels of communication skills in three different disciplines. Croatian Journal of Education, 22(1), 207-240.

Jdaitawi, M. et al. (2013). Students' perspectives on university experiences; The role of protective factors in students life. International Education Studies, 6(7), 239-246.

Jdaitawi, M., Al-Mutawa, A., \& Talafha, F. (2014). Stress and psychological strain among university lecturers in Saudi Arabia. Global Conference on Business \& Finance Proceeding, 9(1), 361.

Karpicz, J. (2020). Just my being here is self-advocacy": Exploring the self-advocacy experiences of disabled graduate students of color. Journal of Committed to Social Change on Race and Ethnicity, 6(1).

Kissel, H. (2006). Self-advocacy programs for college students with disabilities: A framework for assessment. Paper presented at the Annual meeting of the American educational research association, San Francisco, USA.

Kinney, A. \& Eakman, A. (2017). Measuring self-advocacy skills among students veterans with disabilities: Implications for success in postsecondary education. Journal of Postsecondary Education and Disabilities, 39(4), 343-358.

Reed, M., Kennett, D., \& Emond, M. (2015). The influence of reasons for attending university on university experience: A comparison between students with and without disabilities. Active Learning in Higher Education, 16(3), 225-236. DOI: 10.1177/1469787415589626.

Reed, M., Kennett, D., \& Lewis, T. (2011). The relative benefits found for students with and without learning disabilities taking a first-year university preparation course. Active Learning in Higher Education, 12(2). https://doi.org/10.1177/1469787411402483.

Roberts, E., Song, J., \& Zhang, D. (2016). Review of practices that promote self-advocacy for students with disabilities. Journal of Disability Policy $\quad$ Studies, $209-220$. https://doi.org/10.1177/1044207314540213

Roper, L. (2016). Self-advocacy among colleges students with learning disabilities and/or attention-deficit hyperactivity disorders. Unpublished Doctoral Thesis, University of Kentucky.

Siks, R. (2019). A Phenomenological Study: Examining Self-Advocacy Perceptions of High School Seniors with Specific Learning Disabilities who will be First Generation College Students. Unpublished Doctoral Dissertation, North central University.

Sloane, S. E. (2016). Teaching Self-Advocacy for Students with Developmental Variations in Primary Grades. New York: Bank Street College of Education. Retrieved from http://educate.bankstreet.edu/independentstudies/160. 
Tagayuna, A., Stodden, R., Chang, C., Zeleznik, M., \& Whelley, T. (2005). A two-year comparison of support provision for persons with disabilities in postsecondary education. Journal of Vocational Rehabilitation, 22, 13-21.

Tedla, T. (2017). The Importance of Self-Advocacy Skills for Students with Disabilities in Higher Education for a Full Inclusion and a Glimpse of Ethiopian Case: A Review of Related Literature. Open Access Library Journal, 4, 1-8. doi: 10.4236/oalib.1103174.

Thompson-Ebank, V. (2014). Disability disclosure among college students with psychiatric disabilities in professional majors: Risks and implications for rural communities. Professional Development: The International Journal of Continuing Social Work Education, 17(2), 18-28.

Vaccaro, A. \& Kimball, E. (2017). "It's a very deep, layered topic": Student affairs professionals on the marginality and intersectionality of disability. In E. Kim \& K.C. Aquino (Eds.), Disability as diversity in higher education (pp. 138-152). Routledge.

Walker, A. \& Test, W. (2011). Using a self-advocacy intervention on African American college students ability to request academic accommodations. Learning Disabilities Research \& Practice, 26(3), 134-144. Doi://10.1111/j.1540-5826.2011.00333.x 